\title{
Acidity of gastric contents during nocturnal intragastric drip therapy in patients with duodenal ulcer ${ }^{1}$
}

\author{
J. E. LENNARD-JONES, J. C. D. HART, AND PAMELA B. WILCOX \\ From the Department of Gastroenterology and the Medical Research Council Gastroenterology Research \\ Unit, Central Middlesex Hospital, London
}

EDITORIAL SYNOPSIS This report shows that an intragastric milk drip alone has a poor antacid action upon the nocturnal gastric secretion in duodenal ulcer patients. Milk containing $20 \mathrm{~g}$. of sodium bicarbonate per litre is more effective and superior to a chelated aluminium compound, Glymaxil, given in $5 \%$ or $10 \%$ solution. About three-quarters of the gastric samples from the milk-bicarbonate trial were less acid than $p \mathbf{H} 4$.

The acidity of the gastric contents in patients with duodenal ulcer tends to be greater than normal and to reach its maximum at night (James and Pickering, 1949). During waking hours, patients can reduce the acidity by taking frequent doses of antacid. To reduce nocturnal acidity, Winkelstein (1932) introduced intragastric drip therapy, using a solution of sodium bicarbonate in milk. Price and Sanderson (1956) showed that very large amounts of sodium bicarbonate must be given in this way to achieve complete neutralization of the gastric contents, and with these doses systemic alkalosis occurs (van Goidsenhoven, Gray, Price, and Sanderson, 1954). Poorly absorbed antacids have been given by continuous drip, notably aluminium hydroxide and aluminium phosphate, both of which are viscous and require special apparatus (Cornell and Hollander, 1942), and magnesium bicarbonate (Clark, 1950a), which is laxative. A recently introduced chelated aluminium compound, sodium gluconatodihydroxoaluminate III (Glymaxil), can be administered easily and is said to be poorly absorbed.

Milk alone is sometimes administered by intragastric drip to patients with duodenal ulcer. No study has been made of its effect on the acidity of the gastric contents as compared to an inert control solution. The present study compares the effects of milk, milk and sodium bicarbonate, Glymaxil in two concentrations, and a control solution on the acidity of the gastric contents at night in patients with duodenal ulcer. This investigation has been limited to the effectiveness of these liquids as antacids;

1 This work was included in a thesis submitted by one of the authors (J.E.L-J.) to the University of Cambridge for the degree of M.D. possible metabolic effects and therapeutic benefits have not been studied.

\section{METHOD}

The acidity of the gastric contents of 15 patients with a radiologically proven uncomplicated duodenal ulcer was studied by a sampling technique on five nights between 10 p.m. and 6 a.m. Details of the patients' age and sex and of the results of gastric function tests are shown in Table I. The samples were obtained through a fine $(10 \mathrm{Fr})$ radio-opaque nasogastric tube placed fluoroscopically so that the aspiration holes lay in the likely position of the gastric antrum. Before each sample was aspirated, $20 \mathrm{ml}$. of air was injected down the tube to clear it and to agitate the gastric contents around its tip; after each sample had been withdrawn, $10 \mathrm{ml}$. of water was injected down the tube to flush its lumen. Aspiration in this way was performed hourly on the hour between $10 \mathrm{p} . \mathrm{m}$. and 6 a.m. by the nursing staff, who were instructed in the technique, and supervised during the early hours of the night by one of the authors. Each morning the samples were stored in a refrigerator until their $p \mathrm{H}$ was measured with a sealed glass electrode.

A different test liquid was given on each of the five nights through a fine rubber tube tied to the sampling tube, the tip of the drip tube being $25 \mathrm{~cm}$. proximal to the tip of the sampling tube. The order of administration of the test liquids was varied from patient to patient in a Latin-square pattern. The liquids tested were:

(1) Control solution: $5 \%$ dextrose coloured with an inert groen dye to resemble the Glymaxil solutions; (2) milk; (3) milk containing $20 \mathrm{~g}$. of sodium bicarbonate per litre; (4) Glymaxil, $5 \%$ of the proprietary preparation by volume in water, containing $20 \mathrm{~g}$. of the aluminium compound (and $20 \mathrm{~g}$. of sucrose) per litre; (5) Glymaxil, $10 \%$ of the proprietary preparation by volume in water, containing $40 \mathrm{~g}$. of the aluminium compound (and $40 \mathrm{~g}$. of sucrose) per litre. 
TABLE I

DETAILS OF THE AGE, SEX, RESULTS OF GASTRIC SECRETORY STUDIES, AND THE ACIDITY OF GASTRIC SAMPLES FOR EACH PATIENT

\begin{tabular}{|c|c|c|c|c|c|c|c|c|c|c|c|c|}
\hline \multirow[t]{2}{*}{ Patient } & \multirow[t]{2}{*}{$\operatorname{Sex}$} & \multirow{2}{*}{$\begin{array}{l}\text { Ag } \epsilon \\
(y r .)\end{array}$} & \multicolumn{3}{|c|}{ Secretion ( $m E q . \mathrm{HCl})$} & \multirow{2}{*}{\multicolumn{2}{|c|}{$\begin{array}{l}\text { Uropepsinogen } \\
\text { (units/24 hr.) }\end{array}$}} & \multicolumn{5}{|c|}{ No. of Samples $(\mathrm{p} H \gtrless 2 \cdot 0)$} \\
\hline & & & Basal $^{1}$ & $M . A . O .^{2}$ & P.A.O. ${ }^{3}$ & & & Control & Milk & $\begin{array}{l}5 \% \mathrm{~g} . \\
\text { Glymaxil }\end{array}$ & $\begin{array}{l}10 \% \mathrm{~g} . \\
\text { Glymaxil }\end{array}$ & $\begin{array}{l}\text { Milk + } \\
\text { Bicarbonate }\end{array}$ \\
\hline 1 & $\mathbf{M}$ & 49 & $2 \cdot 3$ & $44 \cdot 1$ & $23 \cdot 7$ & 422 & 480 & 7 & 6 & 4 & 0 & 3 \\
\hline 2 & $\mathbf{M}$ & 41 & 6.6 & $27 \cdot 0$ & $16 \cdot 1$ & 93 & 124 & 7 & 3 & 1 & 0 & 2 \\
\hline 3 & $\mathbf{M}$ & 36 & $8 \cdot 3$ & $35 \cdot 2$ & $27 \cdot 5$ & 331 & 403 & 5 & 1 & 5 & 2 & 1 \\
\hline 4 & $\mathbf{F}$ & 42 & $3 \cdot 1$ & $31 \cdot 2$ & 16.7 & 366 & 76 & 8 & 5 & 1 & 1 & 2 \\
\hline 5 & $\mathbf{M}$ & 53 & 0.8 & 28.7 & $15 \cdot 2$ & 264 & 247 & 2 & 1 & 0 & 0 & 0 \\
\hline 6 & $\mathbf{M}$ & 43 & $2 \cdot 2$ & 28.9 & $16 \cdot 8$ & - & - & 5 & 7 & 3 & 1 & 3 \\
\hline 7 & $\mathbf{F}$ & 50 & 0.7 & $23 \cdot 7$ & 13.9 & 174 & 408 & 4 & 0 & 2 & 1 & 0 \\
\hline 8 & $\mathbf{M}$ & 37 & $2 \cdot 8$ & $37 \cdot 7$ & $24 \cdot 6$ & 664 & 663 & 7 & 7 & 2 & 2 & 4 \\
\hline 9 & $\mathbf{M}$ & 29 & $1 \cdot 2$ & $34 \cdot 8$ & 19.6 & - & - & 5 & 5 & 2 & 2 & 0 \\
\hline 10 & $\mathbf{M}$ & 61 & $1 \cdot 3$ & $33 \cdot 2$ & $19 \cdot 4$ & 168 & 132 & 7 & 2 & 0 & 0 & 0 \\
\hline 11 & $\mathbf{M}$ & 42 & 0.5 & 39.0 & $22 \cdot 6$ & 180 & 153 & 7 & 5 & 3 & 0 & 1 \\
\hline 12 & $\mathbf{M}$ & 36 & $4 \cdot 0$ & 36.7 & 20.6 & 347 & 585 & 7 & 5 & 2 & 3 & 1 \\
\hline 13 & $\mathbf{M}$ & 29 & 14.9 & $35 \cdot 4$ & 19.4 & 343 & 306 & 7 & 2 & 2 & 1 & 1 \\
\hline 14 & $\mathrm{~F}$ & 68 & $0 \cdot 1$ & $21 \cdot 5$ & 12.5 & 132 & 122 & 0 & $\mathbf{0}$ & 0 & 0 & 1 \\
\hline
\end{tabular}

${ }^{2}$ M.A.O. = one hour after histamine acid phosphate $0.04 \mathrm{mg}$. $/ \mathrm{kg}$. body weight

${ }^{3}$ P.A.O. = peak half-hour after histamine acid phosphate $0.04 \mathrm{mg} . / \mathrm{kg}$. body weight

'Two 24-hour urine specimens estimated by a modification of the method of Sircus (1954)

Normal values for men $=144 \pm 79$ units $/ 24 \mathrm{hr}$.

Normal values for women $=95 \pm 52$ units $/ 24 \mathrm{hr}$.

The patients took a normal ward diet during the day and a milk drink during the evening. A control sample was aspirated at $10 \mathrm{p} . \mathrm{m}$. and a hypnotic was then given. No other drugs, no alkalis, and no food were taken during the test periods. One litre of a test liquid was given each night by continuous intragastric drip between $10 \mathrm{p} . \mathrm{m}$. and $6 \mathrm{a} . \mathrm{m}$. The total volume was divided into two portions of $500 \mathrm{ml}$., one to be given between 10 p.m. and 2 a.m. and the other to be given between 2 a.m. and 6 a.m. The nurses were encouraged to adjust the speed of the drip from time to time so that the test liquid was given at a steady rate.

\section{RESULTS}

TITRATION IN VITRO The results of titrating $10 \mathrm{ml}$. of each of the test liquids against $0 \cdot 1 \mathrm{~N} \mathrm{HCl}$ are

종

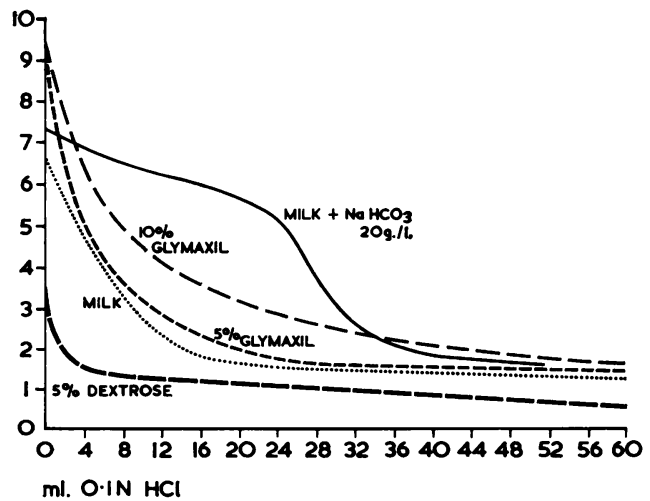

FIG. 1. Results of titration in vitro of the test liquids with $0 \cdot 1 \mathrm{~N} \mathrm{HCl}$. shown in Figure 1. The buffering power of the test liquids was found to increase in the order, control solution $<$ milk $<5 \%$ Glymaxil $<10 \%$ Glymaxil $<$ milk and bicarbonate.

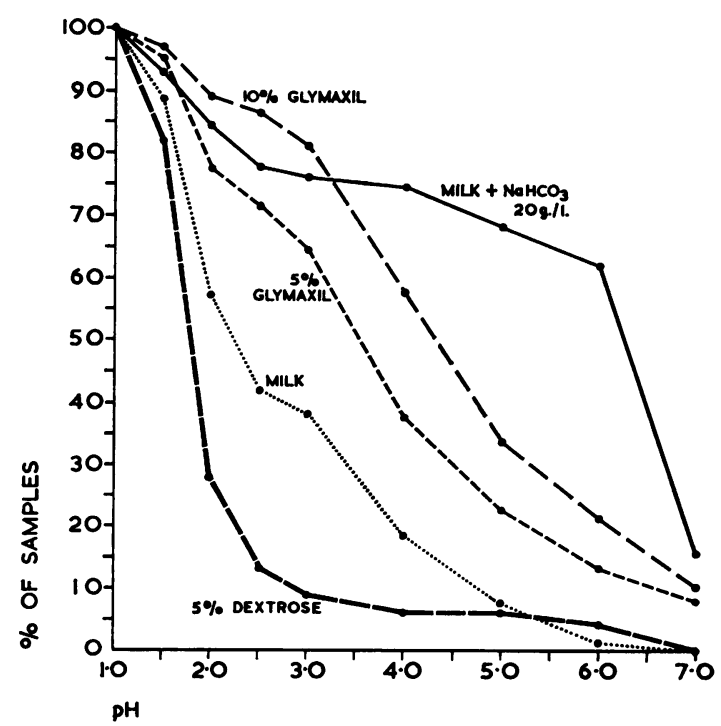

FIG. 2. Cumulative diagram showing the proportion of gastric samples less acid than a given $\mathrm{pH}$ for each of the test liquids.

ACIDITY OF THE GASTRIC SAMPLES The results for all the patients have been pooled so that for each test liquid a maximum of 120 samples is available for 
analysis. The frequency with which samples of different acidity were found with each treatment is shown graphically in Fig. 2, a cumulative diagram which shows the proportion of samples less acid than any given $p \mathrm{H}$. These curves are similar in sequence to those obtained by titration of the test liquids in vitro. The proportion of samples of low acidity tends to increase progressively in the order, control solution $<$ milk, $<5 \%$ Glymaxil $<10 \%$ Glymaxil $<$ milk and bicarbonate. Over $60 \%$ of the samples with milk and bicarbonate were less acid than $p \mathrm{H} \mathrm{6.5}$. Only $28 \%$ of the samples were less acid than $p \mathrm{H} 2$ during administration of the control solution compared with $57 \%$ with milk and over $75 \%$ with the other solutions.

The same results are shown in a different form in Table II, in which the number of samples in different $p \mathrm{H}$ ranges are set out. As one passes down the table the proportion of samples more acid than $p \mathrm{H} 4$ decreases and the proportion less acid than $p \mathrm{H} 4$ increases.

TABLE II

\begin{tabular}{|c|c|c|c|c|c|c|}
\hline \multicolumn{7}{|c|}{$\begin{array}{l}\text { DISTRIBUTION OF SAMPLES IN DIFFERENT } p H \\
\text { RANGES } \\
\text { No. of Samples in Different } \mathrm{pH} \text { Ranges }\end{array}$} \\
\hline & $\gtrless 1.5$ & $1 \cdot 6-2$ & $2 \cdot 1-4$ & $4 \cdot 1-6$ & $>6$ & Total \\
\hline Control & 21 & 63 & 26 & 2 & 5 & 117 \\
\hline Milk & 13 & 38 & 46 & 20 & 1 & 118 \\
\hline $5 \%$ Glymaxil & 6 & 22 & 48 & 28 & 16 & 120 \\
\hline $10 \%$ Glymaxil & 3 & 10 & 38 & 42 & 25 & 118 \\
\hline Milk + bicarbonate & 8 & 11 & 12 & 16 & 73 & 120 \\
\hline
\end{tabular}

The results have also been assessed by considering the solutions in pairs and subtracting the values for the corresponding samples at each hour of the night for each patient. The mean of these differences over the two nights for each patient has been calculated. From the mean difference for each patient, the mean difference for all the patients has been determined and the significance assessed by Student's $t$ test (Table III). The mean shows a significant departure from zero $(P<0.01)$ in every case.

\section{TABLE III}

MEAN DIFFERENCES BETWEEN SAMPLES TAKEN AT CORRESPONDING TIMES IN THE SAME PATIENT FOR THE FIVE TEST LIQUIDS TAKEN IN PAIRS

\begin{tabular}{llll} 
Test Liquid & & $\begin{array}{c}\text { Differences } \\
\text { Mean }(S . E .)\end{array}$ & $\begin{array}{l}P^{1} \\
(n=14)\end{array}$ \\
\hline A Control & B-A & $+0.64( \pm 0.20)$ & $<0.01$ \\
B Milk & C-B & $+0.96( \pm 0.22)$ & $<0.001$ \\
C $5 \%$ Glymaxil & D-C & $+0.69( \pm 0.21)$ & $<0.01$ \\
D $10 \%$ Glymaxil & E-D & $+0.86( \pm 0.24)$ & $<0.01$ \\
E Milk and bicarbonate & & & \\
'The probability that these differences represent a real departure from \\
zero is shown.
\end{tabular}

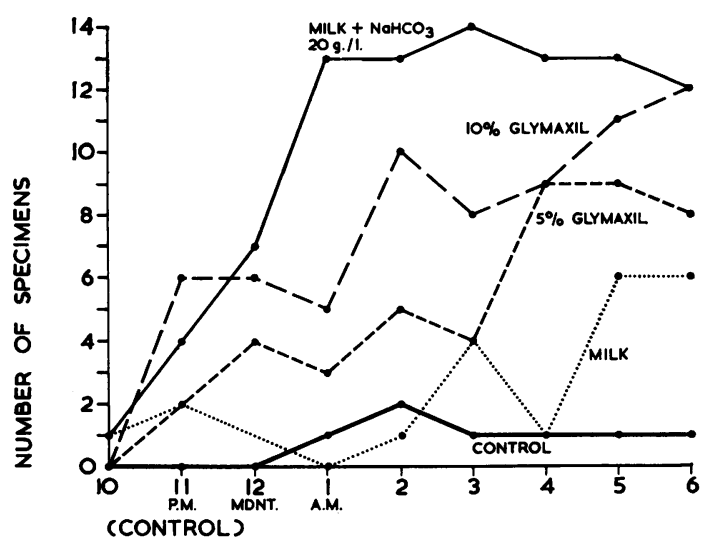

FIG. 3. The number of specimens less acid than $\mathrm{pH} 4$ at each hour of the night for each of the test liquids (maximum number $=15$ ).

CHANGES IN ACIDITY FROM HOUR TO HOUR DURING THE NIGHT The number of specimens less acid than $p \mathrm{H} 4$ at each hour of the night is shown in Figure 3. With each test liquid, the number of samples of low acidity tended to increase as the hours passed. No more than two out of the possible 15 samples were less acid than $p \mathrm{H} 4$ at any hour with the control solution, whereas with milk and sodium bicarbonate 12 to 14 of the possible 15 samples were less acid than $p \mathrm{H} 4$ between 1 and 6 a.m.

COMPARISON OF THE RESULTS OBTAINED WITH GASTRIC FUNCTION TESTS Results of gastric function tests performed on the patients are set out in Table I and are compared with the number of samples obtained of $p \mathrm{H} \gtrless 2$. No correlation is apparent.

\section{DISCUSSION}

Milk is widely used in the dietary treatment of duodenal ulcer. Douthwaite (1947) recommended a continuous intragastric drip of milk as a good method of neutralizing the gastric contents. However, in three patients with duodenal ulcer receiving this treatment, Douthwaite and Hunt (1950) found that 11 of 25 gastric samples were more acid than $p \mathrm{H} 1 \cdot 5$. From measurements of the chloride concentration in the samples they calculated that the patients were secreting 183, 194, and $350 \mathrm{ml}$. of gastric juice each hour, suggesting that the milk was acting as a stimulus to gastric secretion. Thus, although the buffering power of milk can be demonstrated in vitro (Freezer, Gibson, and Matthews, 1928), this effect might be outweighed by the stimulus which it provides to gastric secretion. The present results show that the acidity of the gastric contents is 
reduced by 1 litre of milk given over eight hours. Winkelstein (1932), when he introduced continuous intragastric drip therapy, used milk containing $5 \mathrm{~g}$. of sodium bicarbonate in $1,200 \mathrm{ml}$. (one level teaspoon to the quart). With Cornell and Hollander (1942), he showed in a group of nine patients (eight duodenal ulcer, one gastric ulcer) receiving $1,200 \mathrm{ml}$. of this solution every eight hours, that $30.2 \%$ of gastric samples aspirated through the drip tube during the night were more acid than $p \mathrm{H} 2 \cdot \mathbf{0}$. Seeking to achieve almost complete neutralization, Doll et al. (1956) found in 15 patients with duodenal ulcer that 60 to $140 \mathrm{~g}$. of sodium bicarbonate, dissolved in about $3 \mathrm{l}$. of milk, was needed to maintain the gastric contents at an acidity less than $p \mathrm{H} 4$ throughout the 24 hours. This criterion is very strict and the present study was designed to test the effect of a smaller amount of sodium bicarbonate given at night only. The results have shown that with $20 \mathrm{~g}$. of sodium bicarbonate, dissolved in one litre of milk, and given over eight hours, $19 \%$ of samples (mainly during the first two hours of the drip) were of high acidity $(p \mathrm{H} \gtrless 2 \cdot 0)$ and $73 \%$ were less acid than $p \mathrm{H} 6$.

Sodium bicarbonate is thus an effective antacid but the large amounts needed tend to produce a metabolic alkalosis (van Goidsenhoven et al., 1954). Poorly absorbed antacids have therefore been substituted. Woldman and Rowland (1936) gave aluminium hydroxide by continuous intragastric drip and it is almost as effective as milk containing 4 g. of sodium bicarbonate per litre (Cornell, Hollander, and Winkelstein, 1942). Most workers, however, have found it inconvenient to administer (Clark, 1950a) as the gel tends to sediment and block the drip tube even when a specially designed apparatus (Cornell and Hollander, 1942) is used. Aluminium phosphate is less viscous, is equally effective (Cornell et al., 1942), and is less constipating. Clark (1950a) used a solution of magnesium bicarbonate but during this treatment $39 \%$ of gastric samples were more acid than $p \mathrm{H} 2$ (Clark, 1950b).

The water-soluble chelated aluminium compound tested in this study proved to be a convenient and effective antacid. Using a $10 \%$ solution of the proprietary preparation $(4 \mathrm{~g}$. of aluminium compound per $100 \mathrm{ml}$.), $81 \%$ of samples were less acid than $p \mathrm{H} \mathrm{3,} \mathrm{compared} \mathrm{with} 76 \%$ with the milk and bicarbonate solution. The milk and bicarbonate solution was more effective than $10 \%$ Glymaxil in reducing the acidity to lower levels. A 5\% solution of Glymaxil was a more effective antacid than milk alone. One patient in this series complained of diarrhoea during the administration of Glymaxil, and this side-effect has been noted occasionally in other patients.
No controlled therapeutic trial of antacid drip therapy for duodenal ulcer has been carried out. In patients with gastric ulcer, Doll et al. (1956) in a controlled trial found that an alkaline milk drip did not affect the healing rate. It is known, however, that duodenal ulcers tend to be associated with gastric hypersecretion of acid, whereas there is no such association with ulcers situated in the body of the stomach. The results of a trial of therapy for gastric ulcer do not therefore necessarily hold good for duodenal ulcer. It is commonly stated on theoretical grounds that, to be effective, a treatment for duodenal ulcer should reduce the acidity of the gastric contents to at least $p \mathrm{H} 3 \cdot 5$. Although the acidity, i.e., the concentration of acid, of the gastric contents at night in patients with duodenal ulcer is significantly greater than in normal subjects (Watkinson, 1951), the increase is probably less than ten-fold. For example, Atkinson and Henley (1955) found that $74 \%$ of gastric samples obtained at night from their 15 patients with duodenal ulcer were more acid than $p \mathrm{H} 2$ as compared with $56 \%$ of samples obtained from an equal number of subjects without gastrointestinal disease. It seems possible that a reduction of acidity to within the normal range could be beneficial. A controlled therapeutic trial of the effect of antacid therapy upon the healing and prognosis of duodenal ulcer is needed.

\section{SUMMARY}

The effect of four test liquids given by continuous intragastric drip on the acidity of the gastric contents at night has been compared with a control solution in 15 patients with duodenal ulcer.

Milk alone reduced the acidity of the gastric contents but was the least effective of the liquids tested, $18 \%$ of samples being less acid than $p \mathrm{H} 4$ compared with $6 \%$ of samples with the control solution.

Milk containing $20 \mathrm{~g}$. of sodium bicarbonate per litre was the most effective antacid tested, $74 \%$ of samples being less acid than $p \mathrm{H} 4$.

A chelated aluminium compound, Glymaxil, given in two strengths as a solution containing 20 and $40 \mathrm{~g}$. of the compound per litre (5 and $10 \%$ solutions of the proprietary preparation), gave intermediate results.

We thank the nursing staff who made this study possible by taking samples during the night; Dr. F. Avery Jones, Dr. T. D. Kellock, and Dr. E. N. Rowlands, for permission to study their patients and for their help; Dr. G. P. Clein for his help in the early stages of this investigation; Beecham Research Laboratories Ltd., for generous supplies of Glymaxil; and Mrs. I. M. Prentice for the diagrams. 


\section{REFERENCES}

Atkinson, M., and Henley, K. S. (1955). Levels of intragastric and intraduodenal acidity. Clin. Sci., 14, 1-14.

Clark, A. M. (1950a). Continuous drip treatment of peptic ulcer.

Lancet, 1, 435-438.
(1950b). Continuous drip treatment of peptic ulcer. Ibid., 1, 833-834.

Cornell, A., and Hollander, F. (1942). An improved continuous drip apparatus with special reference to the use of alumina gels in the therapy of peptic ulcer. Rev. Gastroent., 9, 354-358.

$\longrightarrow,-$, and Winkelstein, A. (1942). The efficacy of the drip method in the reduction of gastric acidity. Amer. J. dig. Dis., 9, 332-338.

Doll, R., Price, A. V., Pygott, F., and Sanderson, P. H. (1956). Continuous intragastric milk drip in treatment of uncomplicated gastric ulcer. Lancet, 1, 70-73.

Douthwaite, A. H. (1947). Choice of drugs in the treatment of duodenal ulcer. Brit. med. J., 2, 43-47.

- , and Hunt, J. N. (1950). Continuous drip treatment of peptic ulcer. Lancet, 1, 1019.
Freezer, C. R. E., Gibson, C. S., and Matthews, E. (1928). A contribution to the study of 'Alkalis' as therapeutic agents. Guy's Hosp. Rep., 78, 191-198.

Goidsenhoven, G. M. T. van, Gray, O. V., Price, A. V., and Sanderson, P. H. (1954). The effect of prolonged administration of large doses of sodium bicarbonate in man. Clin. Sci., 13, 383-401.

James, A. H., and Pickering, G. W. (1949). The role of gastric acidity in the pathogenesis of peptic ulcer. Ibid., 8, 181-210.

Price, A. V. and Sanderson, P. H. (1956). Alkali requirement for continuous neutralisation of gastric and duodenal ulcer. Clin. Sci., 15, 285-295.

Sircus, W. (1954). Studies of uropepsinogen excretion in gastrointestinal disorders. Quart. J. Med., N.S., 23, 291-306.

Watkinson, G. (1951). A study of the changes in $p \mathrm{H}$ of gastric contents in peptic ulcer using the twenty-four hour test meal. Gastroenterology, 18, 377-390.

Winkelstein, A. (1932). Studies in gastric secretion with a preliminary note on a new method of therapy for peptic ulcer. Amer. $J$. Surg., 15, 523-524.

Woldman, E. E., and Rowland, V. C. (1936). Continuous acid absorption by aluminium hydroxide drip in the treatment of peptic ulcer. Rev. Gastroent., 3, 27-35. 